\title{
DA EXPANSÃO TECNOLÓGICA DO CAPITAL NO CAMPO À PERMANÊNCIA E RESISTÊNCIA CAMPONESA PELA VIA DA EDUCAÇÃO
}

\author{
DE LA EXPANSIÓN TECNOLÓGICA DEL CAPITAL EN EL CAMPO A LA \\ PERMANENCIA Y RESISTENCIA CAMPESINA A TRAVÉS DE LA VÍA DE \\ LA EDUCACIÓN
}

Suzane Tosta Souza

Universidade Estadual do Sudoeste da Bahia (UESB) suzanetosta@gmail.com

Guilherme Matos de Oliveira Universidade Estadual do Sudoeste da Bahia (UESB) ggui995@gmail.com

Joelma Miranda Coutinho de Souza Universidade Estadual do Sudoeste da Bahia (UESB) jm.geo@hotmail.com

\section{Resumo}

O avanço do capital no campo brasileiro, fundamentado no discurso do desenvolvimento e da difusão de tecnologias voltadas ao aumento da produção e da produtividade, além de se estabelecer na forma própria do agronegócio, busca se expandir e se apropriar da produção camponesa. Para tanto, difunde o uso de tecnologias para tais unidades e a ilusão do desenvolvimento que, na prática, se efetiva na perda de sua relativa autonomia frente aos ditames do mercado. Por outro lado, partindo do entendimento das contradições nas quais o capital se reproduz, compreende-se que o campesinato se reafirma enquanto modo de vida - pela preservação de seus valores, quanto enquanto classe social, pelo papel político de 
enfrentamento à subordinação imposta pelo capital. Nessa luta pela reprodução camponesa, a educação do campo emerge como fundamental a fim de fomentar um projeto efetivamente voltado aos interesses daqueles sujeitos que vivem e se reproduzem por meio do trabalho na terra.

Palavras-chave: Capital. Agronegócio. Tecnologia. Agricultura Familiar/Agricultura Camponesa. Educação do Campo.

\section{Resumen}

El avance del capital en el campo brasileño, fundamentado en el discurso del desarrollo y de la difusión de tecnologías volcadas hacia el aumento de la producción y de la productividad, además de establecerse en la propia forma del agro-negocio, se busca la expansión y apropiarse de la producción campesina. Para ello, son difundidas, el uso de las tecnologías para dichas unidades y la ilusión del desarrollo que, en la práctica, se pone en marcha cuando pierde la relación de la autonomía delante de los dictámenes del mercado. Por otro lado, partiendo del entendimiento de las contradicciones en las cuales el capital se reproduce, se entiende que los campesinos se reafirman a respecto del modo de vida - por la preservación de sus valores, en lo referente a la clase social, por el papel político de enfrentamiento a la subordinación impuesta por el capital. En esa lucha por la reproducción campesina, la educación del campo emerge como fundamental con la finalidad de fomentar un proyecto efectivamente volcado hacia los intereses de aquellos sujetos que viven y se reproducen mediante el trabajo en la tierra.

Palabras-clave: Capital. Agro-negocio. Tecnología. Agricultura Familiar/Agricultura Campesina. Educación del Campo.

\section{1- Introdução}

O presente artigo discute a relação entre expansão da tecnologia, reprodução camponesa e educação, que se estabelece de forma contraditória no campo brasileiro, uma vez que o processo de avanço capitalista impulsionado mais recentemente pelo agronegócio como forma de garantir sua reprodução ampliada - e viabilizada pela utilização exacerbada de tecnologias - a exemplo das maquinarias poupadoras de força de trabalho, se impõe e ao 
mesmo tempo se confronta com o modo de vida de centenas e milhares de famílias camponesas que tem no tripé - terra, trabalho e família ${ }^{\mathrm{i}}$ - sua reprodução social.

A expansão do capital no campo, por outro lado, viabiliza formas de se apropriar da efetiva produção camponesa, através do processo de monopolização da produção e dos territórios camponeses, apropriando-se de seus produtos na esfera da circulação e incorporando, sem nenhum sacrifício, parte de sua renda. Nesse processo, difunde-se o conceito de agricultor familiar que possui, ideologicamente, a função de reproduzir o camponês enquanto mera força de trabalho, totalmente assujeitada as demandas do mercado.

Ressalta-se que a difusão da tecnologia no campo (intensificação do capital constante) - seja pelo agronegócio ou pela agricultura familiar - rebate-se negativamente sobre o trabalho, ampliando o desemprego estrutural e gerando um exército de miseráveis expulsos do campo que, em geral, passam a realizar a vida na constante mobilidade de sua força de trabalho. Além disso, para aqueles camponeses que permanecem na terra de trabalho, a tentativa de transformá-los em agricultor familiar atua ideologicamente no sentido de desarticular as ações políticas desses sujeitos. Ao se aceitar que esses camponeses se tornam apenas agricultores familiares, força de trabalho para o capital, ou seja, totalmente subsumidos as definições do mercado, perde-se a dimensão dialética das contradições que se efetiva na própria compreensão da sociedade de classes e da histórica luta dos camponeses para continuar existindo.

Assim sendo, com base na leitura das contradições que se verifica no campo brasileiro (enquanto expressão de uma totalidade) afere-se, com base na análise de Luxemburgo (1985) e através de diversas realidades observadas no campo brasileiro (MARTINS, 1991; CONCEIÇÃO, 1991; OLIVEIRA, 1998 e 2001; FERNADES, 2002; MARQUES, 2002; SOUZA, 2008, dentre outros), que ao invés de desaparecer, os camponeses se reproduzem e desenvolvem formas de permanência no campo. Dentre essas formas de luta camponesa, ressalta-se a consolidação de um projeto específico de educação: a educação do campo, enquanto estratégia de valorização e reprodução do homem do campo, que nesse artigo é apontada a partir da experiência desenvolvida pela Escola Família Agrícola (EFA). Acreditase que ao buscar formas de permanência dos jovens camponeses - a EFA - contrapõe-se aos projetos de expansão do capital - tanto no sentido de incentivar os mesmos a resistirem no campo e não se submeterem totalmente ao assalariamento, quanto por representar um modo 

educação

de viver e se reproduzir (embora também subordinado) que se difere das formas tecnificantes e alienantes impostas pelo mercado.

Portanto, considera-se que a permanência camponesa e a educação do campo constituem-se formas concretas de resistência que o agronegócio (e o próprio capital) encontra para se estabelecer plenamente no campo. Ou seja, há uma relação contraditória entre a expansão da tecnologia e a educação no campo, que evidenciam os conflitos capital versus trabalho, em que os processos de permanência camponesa e a construção de um projeto educacional de fortalecimento dessa identidade representam verdadeiros "enclaves" a consolidação do agronegócio (e da agricultura familiar) como formas únicas de expressar a realidade do campo brasileiro.

\section{2- Expansão do capital no campo: o discurso tecnológico via agronegócio e agricultura familiar}

A expansão do capital no Sudoeste da Bahia, mais especificamente a partir das transformações verificadas no contexto da década de 1970 e posteriores - com a difusão do monocultivo do café, como extensão da efetiva produção já consolidada no Planalto brasileiro, pode ser compreendida no processo de inserção do Brasil na divisão social e territorial do trabalho, que se expressa na forma desigual e combinada através da qual a acumulação se estabelece. Evidencia, desse modo, uma singularidade inserida na totalidade das relações sociais e históricas. Enquanto singularidade ressalta-se que esse processo em muito beneficiou as classes dominantes locais, proprietárias das terras e de outros meios de produção. Essa classe se insere no circuito da produção da mercadoria, se apropriando de recursos financeiros significativos para promover ideologicamente o projeto de “desenvolvimento regional" "ii É nesse contexto, que se pode entender a expansão da produção cafeeira, seguida de outros cultivos e criações no Sudoeste da Bahia, como frutas irrigadas, gado (sobretudo nas áreas de caatinga) e mais recentemente o eucalipto, como cultivos estratégicos fundamentais ao agronegócio brasileiro.

Entender o processo de produção do espaço agrário brasileiro significa considerar que este se faz a partir das contradições existentes entre as classes sociais, ao longo do processo histórico. Para tanto, isto requer considerar as contradições existentes no processo produtivo, na apropriação dos meios de produção e dos recursos naturais e, a partir de então, compreender o papel que cada classe assume no processo produtivo, bem como, de que forma participam e usufruem dos resultados da produção (SOUZA, 2008, p. 182). 
Embora reconhecendo que o Brasil, desde o período colonial, encontrava-se inserido na produção de capital é, sobretudo, a partir da segunda metade do século 20, que o desenvolvimento do capitalismo ganha nova dimensão, dadas as condições históricas favoráveis, a exemplo do crescimento das cidades e a "ideologia da industrialização", como forma de superação da condição de "atraso" que representaria o campo.

O campo passa a sofrer mudanças substanciais nas relações de produção e nas formas de organização existentes até então. O papel do Estado é fundamental na difusão de uma ideologia do "desenvolvimento" que considera as grandes propriedades aquelas preparadas para assumir a "dinâmica" imposta à agricultura mundializada e tecnificada, o que, por outro lado, recai, negativamente, sobre as formas de organização tipicamente camponesas, que por não terem as mesmas condições de modernizar-se ou tenderiam a desaparecer ou se subordinariam as grandes empresas industriais do meio rural.

A "superação do atraso" seria viabilizada pela expansão da indústria em direção a outros setores da economia, na perspectiva de superar a "dicotomia" existente entre esses ramos. Para tanto, seria necessário industrializar o campo, processo que Graziano da Silva (1996) chamou de industrialização da agricultura, no qual a difusão da técnica adquire centralidade.

Na década de 1980, o estudo do setor agroindustrial esteve centrado na noção de complexo agroindustrial também conhecido como CAI. Ao fim desta década os principais pressupostos subjacentes a esse arcabouço teórico passaram a dar sinais de esgotamento, dada constatação de uma presença efetiva de novas ações externas à abrangência desse conceito. (SANTOS, 2003, p. 23).

A partir da década de 1990 o avanço do capital no campo brasileiro se expressa através do conceito de agronegócio (tradução do agribusiness norte-americano), que se baseia no incremento tecnológico aplicado ao campo. O latifúndio é mascarado com o nome de empresa rural. A agricultura se abre aos grandes negócios, voltados ao capital internacional, notadamente o financeiro. Assim, consolidam-se novas formas de apropriação territorial dos recursos e da força de trabalho precarizada, o que significa novas investidas sobre o trabalho.

A concentração da terra é mantida e até se acentua e o tão almejado "desenvolvimento" se concretiza trazendo benefícios para as classes dominantes - os proprietários fundiários, que se apropriam de uma melhor renda da terra, e os capitalistas que veem no campo novas possibilidades de lucros.

Revista RBBA $\mid$ Revista Binacional Brasil Argentina 
Da expansão tecnológica do capital no campo à permanência e resistência camponesa pela via da educação

De acordo com Marcos Sawaya Jank, o agronegócio é um marco conceitual que delimita os sistemas integrados de produção de alimentos, fibras e biomassa, operando desde o melhoramento genético até o produto final, no qual todos os agentes que se propõem a produzir matérias-primas agropecuárias devem fatalmente se inserir (grifo nosso) sejam eles pequenos ou grandes produtores, agricultores familiares ou patronais, fazendeiros ou assentados (Estado de São Paulo, $1^{\circ}$ Caderno, 05/07/2005, p. A2).

É o discurso do desenvolvimento e da técnica como forma de levar a sociedade a um patamar superior. Na prática ocorre um processo de expropriação das terras dos camponeses, desemprego estrutural no campo, concentração das terras e da renda, e a degradação das condições de trabalho (para aqueles que conseguem se manter, precariamente, no processo produtivo).

O Brasil é um dos líderes mundiais na produção e exportação de vários produtos agropecuários. É o primeiro produtor e exportador de café (grifo nosso), açúcar, álcool e sucos de frutas. Além disso, lidera o ranking das vendas externas de soja, carne bovina, carne de frango, tabaco, couro e calçados de couro. As projeções indicam que o país também será, em pouco tempo, o principal pólo mundial de produção de algodão e biocombustíveis, feitos a partir de cana-de-açúcar e óleos vegetais. Milho, arroz, frutas frescas, cacau, castanhas, nozes, além de suínos e pescados, são destaques no agronegócio brasileiro, que emprega atualmente 17,7 milhões de trabalhadores somente no campo. ${ }^{\mathrm{iii}}$

O agronegócio conta com uma estrutura de funcionamento que permite a associação da produção agrícola com os outros setores produtivos, de modo que grande parte dos produtos já sai do campo industrializado, ou beneficiado. Para tanto, o desenvolvimento de pesquisas técnico-científicas, em grandes e médios centros universitários, atende essa demanda do mercado.

O aparato que envolve as atividades voltadas ao agronegócio pode ser classificado em três partes. A primeira corresponde aos negócios agropecuários propriamente ditos (ou de "dentro da porteira") que representam os produtores rurais, sejam eles pequenos, médios ou grandes produtores, constituídos na forma de pessoas físicas (fazendeiros ou camponeses) ou de pessoas jurídicas (empresas). Em segundo lugar, tem-se os negócios à montante (ou "da pré porteira") aos da agropecuária, representados pelas indústrias e comércios que fornecem insumos para os negócios agropecuários; a exemplo dos fabricantes de fertilizantes, defensivos químicos, maquinário de diversos portes (tratores, colheitadeiras, dentre outros), 
etc. Em terceiro lugar, estão os negócios à jusante dos empreendimentos agropecuários. São os negócios "pós-porteira", aqueles que compram os produtos agropecuários, os beneficiam, os transportam e os vendem para os consumidores finais; por exemplo, os frigoríficos, as fábricas de fiação, tecelagem e de roupas, os curtumes e as fábricas de calçados, os supermercados e varejistas de alimentos, etc.

Tem-se assim, todo o circuito da produção, distribuição, circulação e consumo das mercadorias impulsionadas pelo agronegócio, fundamentado na total integração ao mercado e na redenção à produção gerada pelas grandes propriedades. Um discurso do aparente que não se sustenta na prática!

O uso de máquinas, equipamentos, sementes geneticamente melhoradas (transgênicos) e irrigação, a produção de commodities, a concentração fundiária e a desocupação da força de trabalho são características do referido "projeto". Com relação à estrutura fundiária evidenciase que nos locais onde tal "modelo produtivista" se implantou com mais intensidade houve uma concentração das terras nas mãos de poucos e o consequente aumento de miseráveis no campo.

A argumentação de que o agronegócio é o que mais produz no campo brasileiro, por outro lado, é contestada tanto pelos movimentos camponeses quanto por dados oficiais demonstrados via censos agropecuários quando destacam que a maior parte da produção de cultivos como: o feijão, o arroz, a mandioca, a criação de animais (sobretudo de pequeno e médio porte), estão nas pequenas e médias propriedades. Além disso, essas unidades de produção são significativas no cultivo de produtos considerados estratégicos do agronegócio como: o café, o milho, a soja e outros.

Além do mais, não se pode desconsiderar a contradição existente no fato do agronegócio apresentar-se como o que há de mais "moderno" e "eficiente" para o campo brasileiro, mas se efetivar através da reprodução do que há de mais atrasado - as relações de trabalho degradantes (escravas e semiescravas), conforme flagrantes dados por fiscais do Ministério do Trabalho, em diversos latifúndios do país. A exemplo da ação que resgatou 1.108 trabalhadores, no dia 30 de setembro de 2007, em condições análogas à escravidão, na fazenda Pagrisa (Pará Pastoril e Agrícola S.A.), cujo principal cultivo é um dos carros chefes do agronegócio brasileiro - a cana-de-açúcar, localizada no município de Ulianópolis, onde os trabalhadores dormiam em alojamentos superlotados com esgoto a céu aberto, recebiam 
Da expansão tecnológica do capital no campo à permanência e resistência camponesa pela via da educação

comida estragada e água sem condições de consumo, além de salários que chegavam a R\$ 10,00 por mês.

Dentre as estratégias do agronegócio para o campo brasileiro, destaca-se a monopolização da produção e a territorialização do capital (OLIVEIRA, 1998). O capital atua em consonância com os interesses dos grandes proprietários e não raramente pode-se verificar que o capitalista e o proprietário podem ser a mesma pessoa. Neste caso, o capital se territorializa e o capitalista torna-se também grande proprietário, imobilizando parte de seu capital na compra da terra, onde, por meio da produção, possa garantir a apropriação da renda da terra e do lucro, ao transformar a produção em mercadorias. Neste caso, a relação entre capital, técnica e agronegócio se consolida completamente.

Por outro lado, esta não é a única maneira do capital se reproduzir no campo brasileiro, este também busca explorar a força de trabalho camponesa. Esse processo acontece quando o capitalista não se torna proprietário, mas desenvolve formas de se apropriar dos resultados da produção, da renda que deveria ser destinada ao produtor direto. É nessa estratégia que a categoria genérica agricultor familiar, totalmente subsumido ao capital, passa a fazer sentido, em substituição ao conteúdo político e de classe que o camponês representa.

Assim, a difusão do conceito de agricultura familiar pode ser considerada mais uma estratégia do capital para o campo e repercute na tentativa de apropriação do produto gerado pelo trabalho camponês, através do que Martins (1981) denomina de sujeição da renda da terra ao capital. Isto significa que o capital não mais necessita contratar trabalhadores para desempenhar determinadas tarefas, basta a este, agora, sujeitar os pequenos agricultores, os camponeses, que completamente inseridos no circuito produtivo do capital perdem toda sua possibilidade de autonomia, convertendo-se, junto com sua família em mera força de trabalho. Neste sentido, Fernandes (2002) considera:

(...). Que o produtor familiar que utiliza os recursos técnicos e está altamente integrado ao mercado não é um camponês, mas sim um agricultor familiar. Desse modo, pode-se afirmar que a agricultura camponesa é familiar, mas nem toda a agricultura familiar é camponesa, ou que todo camponês é agricultor familiar, mas nem todo agricultor familiar é camponês. Criou-se assim um termo supérfluo, mas de reconhecida força teórico - política. E como eufemismo de agricultura capitalista, foi criada a expressão agricultura patronal. (FERNANDES, 2002, p. 29-30).

O conceito de agricultor familiar passa a ser amplamente difundido a partir da década de 1990 em substituição ao conceito de agricultura camponesa e reflete, exatamente, o avanço

\begin{tabular}{l|l} 
Revista RBBA & Revista Binacional Brasil Argentina
\end{tabular} 
das relações capitalistas de produção, a difusão de pesquisas e tecnologias, que permitiram um desenvolvimento da produção agrícola em níveis nunca vistos antes na história da humanidade. Nessa leitura, o camponês não mais representaria esse novo sujeito do campo, que frente ao acesso a tais incrementos tecnológicos (ainda que de forma subordinada) se modernizou e encontra-se, inteiramente, integrado ao mercado. Assim, os saberes tradicionalmente acumulados que caracterizam o modo de vida camponês não mais faria sentido e ainda poderia funcionar como impeditivo à ampliação das "inovações necessárias" ao campo. No Brasil tal leitura é difundida com as pesquisas desenvolvidas por Ricardo Abramovay (1992) e outros. Estas análises, por outro lado, são fortemente influenciadas pelos estudos desenvolvidos por Hugues Lamarche (1994).

(...). No campo, o aumento da composição técnica/orgânica do capital é desenvolvido de forma desigual e tem como objetivo elevar a produtividade do trabalho sob diversas formas. Esse processo ocorre de forma desigual e contraditória, e envolve a inserção de tecnologias para a redução dos custos sob o controle das grandes transnacionais, um aumento da exploração do trabalho assalariado e simultaneamente do trabalho camponês, subordinando-o às indústrias e aos Bancos. A ampliação da divisão social e territorial do trabalho é um corolário da reestruturação produtiva da agricultura (OLIVEIRA, 2007. p. 183).

Para Carvalho (2005) o conceito de agricultura familiar pode ser entendido como aquele em que: "a família, ao mesmo tempo em que é proprietária dos meios de produção, assume o trabalho no estabelecimento produtivo" (p. 27), portanto associando família, produção e trabalho. Nessa perspectiva a agricultura camponesa tradicional seria uma das formas sociais de agricultura familiar, já que também se origina no trinômio família, produção e trabalho; no entanto, o conceito de agricultura camponesa tem particularidades que a distingue do conjunto da agricultura familiar, que se referem aos objetivos da atividade econômica e sua forma de inserção na sociedade global. Assim sendo, todo camponês pode ser entendido como agricultor familiar, mas nem todo agricultor familiar é camponês. O que define os limites entre ambos é a forma de organização da produção, e obviamente os objetivos desta.

Por isso é que Shanin (1980) chama atenção para o entendimento do campesinato enquanto um conceito político, de enfrentamento ao capital, já que sua lógica de reprodução social difere da ótica capitalista. Esse significado político do conceito de camponês é quem garantiu uma periodicidade de seu próprio uso, sempre refletindo a história social em sentido 
Da expansão tecnológica do capital no campo à permanência e resistência camponesa pela via da educação

amplo, mas também uma dinâmica específica do pensamento acadêmico. Já aqueles que optam em utilizar o conceito de agricultura familiar o fazem aceitando que interessa ao capitalismo reproduzir a força de trabalho familiar, para que por meio dessa possa garantir o processo de sujeição da renda da terra. A leitura que se busca é a das vantagens da inserção do agricultor familiar nos projetos do capital, no qual o sentido de enfrentamento entre classes antagônicas desaparece, assim como todo o conteúdo político e de resistência que o conceito de camponês carrega historicamente.

\section{3- Para além do Agronegócio e da Agricultura familiar: a reprodução e a resistência camponesa}

Partindo da leitura das contradições que permitem compreender a produção do espaço no campo brasileiro, enquanto expressão concreta da sociedade composta por classes sociais antagônicas, o referido artigo acata o entendimento de que o processo de expansão do capital, sobretudo através da consolidação do agronegócio e da agricultura familiar, assim como a predominância do trabalho assalariado no campo brasileiro, não caracteriza, nem definem todas as formas de viver e se reproduzir. Assim sendo, entende que há um processo de reprodução/sujeição do campesinato enquanto expressão das próprias contradições da reprodução do capital. Referenda assim a teoria desenvolvida por Rosa de Luxemburgo (1985) para a qual a produção do capital não se estabelece por meio de relações capitalistas (assalariadas), mas por meio de relações não capitalistas, através das quais a reprodução camponesa adquire maior sentido.

Ao capital interessa reproduzir, para explorar, a força de trabalho e se apropriar da produção camponesa, sem ter que investir recursos no pagamento do salário, mas, não interessa reproduzir o conteúdo político, de classe, do campesinato. Eis a contradição! No entanto, os camponeses, seja enquanto um modo de vida, seja enquanto classe social se reproduzem no campo, referendando-se na tríade terra-trabalho-família e, por diversas vezes, enfrentam as investidas do capital, seja negando-se a sair da terra, seja lutando por esta, ou ainda mantendo uma relativa autonomia do que e como produzir.

Os estudos sobre o campesinato tomam novo fôlego a partir das análises desenvolvidas por Teodor Shanin, dado número de pesquisas que este consegue reunir sobre os camponeses, em diversas partes do mundo, constatando que mesmo diante de algumas diferenças, tais comunidades apresentam, por outro lado, uma determinada coesão em termos 
de organização social, formas de uso da terra, vínculos familiares, dentre outras características. Além disso, o autor destaca as formas de pressão política exercidas por essa classe, em diversos países do mundo - a exemplo do movimento liderado pelos zapatistas, em Chiapas, no México, diferente das análises nas quais o campesinato não reuniria as condições de desempenhar um papel político significativo, tendo em vista a dispersão em que viviam.

O próprio avanço das relações capitalistas e as contradições oriundas da necessidade de expansão de seus projetos no campo acabam por exigir dos camponeses uma participação política mais efetiva. Ainda que, inicialmente, tal articulação se faça no intuito de manutenção da terra da família, a constante ameaça de perda da terra, os impulsionam a lutarem para não perderem sua condição de reprodução social. Além disso, aqueles camponeses que se "integram" completamente ao mercado veem seus anseios de liberdade, ainda que parcial, sucumbirem frente às demandas do capital. A perda do controle do trabalho, e seus reflexos nos costumes e valores da família camponesa repercute, diretamente, em tentativas concretas de enfrentamento a lógica hegemônica.

(...) O camponês trabalha a terra para se nutrir (...). Mas o camponês produz também para o mercado envolvente (...). No entanto, essa exigência não é mais que um acessório para compreender a lógica que preside o cálculo econômico camponês. Por camponês, é necessário entender a família camponesa (...) que conta ao mesmo tempo os braços que trabalham e as bocas que têm de ser alimentadas: (...) a família vive de uma terra que é sua e que lhe é própria, o que não quer dizer que tenha sempre a plena propriedade, no sentido privativo do direito romano; mas ela dispõe ao menos do direito de explorar essa terra (...). Sendo o modo de vida fixado pelo costume. $\mathrm{O}$ trabalho não é remunerado (...). A terra não é propriamente um capital, no sentido capitalista do termo, já que não engendra lucro (MENDRAS, 1978, p. 44 a 47).

Vê-se assim, uma lógica que se contrapõe a perspectiva hegemônica do mercado. Os valores camponeses e sua pressão política para continuar existindo, pode ser vista então como um empecilho a difusão tecnológica e alienante da produção capitalista para o campo - onde o fundamento inicial e último é a exploração da força de trabalho para produzir valores de troca. É nesse propósito que se pode compreender as investidas para "integrar" a produção camponesa ao mercado, que se estabelece na estratégia de difusão de incrementos e tecnologias que definem o que, quanto e como produzir. Um exemplo claro disso é a “inserção" de pequenos agricultores às industriais de frangos do Sul do país. Ao se integrar sobre o discurso do emprego e da renda os camponeses perdem totalmente a autonomia do seu 
Da expansão tecnológica do capital no campo à permanência e resistência camponesa pela via da educação

ser social. Mas, esse processo não se unifica em todo campo brasileiro e não se estabelece sem contradições.

Em contraponto a essa leitura Shanin (1980) aponta a relativa autonomia da classe camponesa, produtora direta dos seus meios de reprodução social, ao menos os bens básicos, que prevalece em diversas unidades familiares, daí a relevância e a importância desta classe na sociedade capitalista atual. Sobre o papel político exercido pelo campesinato, é preciso que se considere que as mudanças na sociedade, mediante o próprio avanço do capital, a expansão de tecnologias no campo (muito embora sua distribuição seja desigual), a abertura de estradas, o acesso à educação e a saúde, dentre outros, à população do campo, faz com que se possa questionar o fato do campesinato não ter as condições de se articular politicamente. Ou seja, a difusão de serviços e tecnologias voltados a reprodução ampliada do capital traz também o seu revés, a possibilidade de apropriação, ainda que desigual, de tais recursos como forma de fortalecimento, articulação e reprodução do campesinato.

Por isso, pensar o campesinato atualmente significa, logicamente, considerar as relações que esse desenvolve com outras classes sociais, e com o urbano, mais especificamente, enquanto produtor de alimentos e criadores de animais que serão, em sua maioria, consumidos nas cidades. Mas o fato de não mais viverem, na maioria das vezes, em “comunidades isoladas" não significa que esses percam seus costumes, valores e forma de organização social, embora sofram influência crescente das cidades e do modo de vida urbano - em destaque os filhos dos camponeses, cuja mobilidade para a cidade se faz, muitas vezes, na busca de garantir o trabalho. Ao passo que o contato indissociável entre campo e cidade, entre camponeses e outras classes sociais, pode representar um impacto nas formas de vida, pode, por outro lado, ser extremamente interessante para esses sujeitos do ponto de vista da sua atuação política - principalmente quando articulados em movimentos sociais.

Argumenta Shanin (1980) que em países como o México o número de camponeses se mantem estável, e no Brasil este número tem aumentado bastante, sendo tal fato reconhecido pelo Banco Mundial, que passa a ver nestes sujeitos novas formas de possibilidades para o capital. Contudo, em recente conferência realizada no Brasil, Teodor Shanin (2007) mesmo considerando a relevância da economia camponesa, inclusive demonstrando exemplos de como esses vão desenvolvendo formas de resolver seus problemas alimentares e de sobrevivência da família -adquirindo uma lógica própria que não desapareceu durante o tempo, aceita a ideia de que nos países europeus, por conta de todo desenvolvimento técnico

\begin{tabular}{l|l} 
Revista RBBA & Revista Binacional Brasil Argentina
\end{tabular} 
aplicado na agricultura exista, de fato, uma tendência ao desaparecimento do camponês, o que não será possível em várias outras partes do mundo, como os países da América Latina, em que novas possibilidades de recriação do campesinato estão em curso.

(...) sob certas condições, os camponeses não se dissolvem, nem se diferenciam em empresários capitalistas e trabalhadores assalariados, e tampouco são simplesmente pauperizados. Eles persistem, ao mesmo tempo que se transformam e se vinculam gradualmente à economia capitalista circundante, que pervade suas vidas. Os camponeses continuam a existir, correspondendo a unidades agrícolas diferentes, em estrutura e tamanho, do clássico estabelecimento rural camponês. (SHANIN, 1980, p. 58).

Com isso, os camponeses são marginalizados e a importância da agricultura camponesa dentro da economia nacional diminui; entretanto, esta não desaparece e cria novas formas de resistência no campo. A agricultura demora a ser capturada e não pode ser definida simplesmente como capitalista. Mas esta passa a apresentar alguns tipos de vinculação com o capitalismo, convivendo ao lado de características camponesas específicas. Portanto, torna-se fundamental conhecer a forma como a família organiza sua produção e busca por meio dessa garantir sua reprodução social.

É preciso compreender os processos sociais e seu desenrolar ao longo do movimento da história, o que significa pensar o campesinato se reproduzindo numa sociedade capitalista, sendo influenciada pelos seus princípios e a esse subordinado. No entanto, a terra da família camponesa, a possibilidade de laços de solidariedade entre as comunidades, a luta dos camponeses e sua participação política - via organizações em movimentos sociais reivindicatórios, e outros, podem vir a ser um indicativo importante na condução da superação de uma visão individualista e familiar (no máximo comunitária), quiçá alçar uma perspectiva mais coletiva, que redunde em uma verdadeira e definitiva aliança operário camponesa, capaz de enfrentar a lógica opressora capitalista, e promover mudanças qualitativas reais e fundamentais na sociedade.

Uma das expressões mais evidentes para a permanência na terra, ou mesmo de resistência camponesa - pela via da ocupação, tem sido o debate em torno do fortalecimento dos valores camponeses. Nesse processo, a educação do campo torna-se fundamental. É partindo dessa premissa de uma educação fundamentada em valores camponeses e da realidade concreta, que no caso das comunidades rurais pesquisadas se efetiva através da experiência da Escola Família Agrícola, que se pode pensar formas efetivas não apenas de 
Da expansão tecnológica do capital no campo à permanência e resistência camponesa pela via da educação

permanência e reprodução camponesa, quanto de tentativas de enfrentamento a lógica hegemônica e tecnificante que se coloca como projeto do capital para o campo brasileiro.

\section{4- A Escola Família Agrícola (EFA): educação e permanência dos camponeses na terra}

A construção de um projeto educacional efetivamente do campo faz parte das bandeiras de reivindicações dos Movimentos Sociais Rurais. Entende-se, portanto, que não basta estender o oferecimento da educação pública na direção das comunidades rurais, ou seja, se ter uma educação no campo. É preciso que se tenha uma educação concretamente fundamentada nos valores camponeses. Uma educação que valorize sua cultura e formas de luta na permanência da terra de trabalho. Portanto, verifica-se uma relação com a tríade apontada por Thompson (2002) quanto aos valores que fundamentam a vida camponesa: a terra, o trabalho e a família. Nesse processo, o trabalho na terra garante a reprodução social da família. A terra é assim condição e produto do trabalho e de vida dos sujeitos que nestas se reproduzem.

O debate em torno da Educação do Campo, portanto, pode ser compreendido como uma opção política: primeiro de enfrentamento a um projeto educacional fundamentado nos valores urbanos e distanciado da lógica camponesa, o que acaba por funcionar como um atrativo a saída dos jovens do campo em direção aos centros urbanos, enfraquecendo a luta camponesa; segundo como estratégia de sobrevivência, não apenas do modo de vida camponês, mas das lutas históricas e mesmo de enfrentamento aos projetos do capital - via agronegócio, que busca se impor no campo brasileiro.

Em pesquisas realizadas em comunidades camponesas do município de Anagé, no Sudoeste da Bahia, onde predomina a vegetação de caatinga, Souza (2008) apontou a importância da Educação fundamentada nos valores camponeses, por meio da Escola Família Agrícola (EFA), considerada pelos pais dos jovens estudantes uma questão central no despertar desses para a manutenção da terra de família. Além disso, os conhecimentos adquiridos na escola são de grande valia para tocar a produção, com o desenvolvimento de técnicas agrícolas simples e em harmonia com a natureza.

No que concerne à educação, parte dos filhos dos camponeses se desloca diariamente para a cidade de Anagé onde dão continuidade aos estudos, com destaque a Escola Família Agrícola (EFA), voltada à realidade do universo

\begin{tabular}{l|l} 
Revista RBBA & Revista Binacional Brasil Argentina
\end{tabular} 
camponês. Como a proposta da EFA é a de criar as condições objetivas para a valorização do campo, incentivando os jovens a permanecerem nas unidades de produção das famílias, o calendário escolar desenvolve-se de forma adaptada as necessidades das famílias. Além disso, os conhecimentos teóricos devem ser aplicados na prática, onde após 15 dias de aula consecutivas (manhã e tarde) os educandos passam 15 dias nas roças, aplicando os conhecimentos adquiridos nas escolas. Na EFA de Anagé, existe o ensino até a $8^{\mathrm{a}}$ série do fundamental. Terminado este período, o nível médio é apenas oferecido na EFA de Riacho de Santana, há mais de $200 \mathrm{~km}$ da localidade. Os pais entrevistados têm todo interesse em manter os filhos nesta escola, mas demonstram as dificuldades concretas de manterem os custos de terem filhos estudando em outra cidade. É interessante destacar que os camponeses que possuem filhos na EFA declaram-se plenamente satisfeitos, destacando a ajuda que os filhos já dão para continuar a produção, orientação no plantio, etc., inclusive contribuindo para melhorar a produção; em que determinados conhecimentos os próprios pais não tiveram acesso. No período da vivência os estudantes da EFA que residem na comunidade de Caçote encontravam-se em atividade escolar. Verificou-se, em campo, em visita às roças, algumas experiências já colocadas em prática, por estes jovens que darão continuidade às unidades de produção de seus pais, o que não ocorre em uma escola comum, ainda que seja no meio rural. (SOUZA, 2008, p. 615-616).

A pedagogia da alternância, fundamentada nos princípios educacionais defendidos pelo educador brasileiro Paulo Freire, referenda a necessidade de um saber para a realidade prática, cuja metodologia se concretiza através do calendário escolar dividido entre o tempo da escola e o tempo da comunidade, onde todos os conhecimentos adquiridos em sala de aula são utilizados para o trabalho na terra de família.

A educação, nesse processo, não é algo que se distancia da vida prática, da luta camponesa para continuar se reproduzindo, portanto, possui um claro compromisso social e político. Ao assumir tal compromisso, a educação para a vida acaba por se converter em importante estratégia de resistência, contrapondo-se aos valores do mercado, do entendimento da terra e da produção como meras mercadorias, produtoras de valores de troca. Na educação do campo, a terra é apontada como lócus de vida e trabalho, valor de uso, onde se torna possível ainda se perceber algum nível de apropriação do produto do trabalho, em detrimento da lógica alienante do trabalho subsumido ao valor de troca.

Com base nessa relevância da Educação do campo, estudos realizados por Camacho (2012), Souza (2008), Oliveira (2001), Silva (2001), entre outros, refletem a necessidade de um entendimento, tanto social quanto histórico, das singularidades do espaço rural, quanto das disparidades estabelecidas entre campo-cidade - no processo de reprodução capitalista, 
Da expansão tecnológica do capital no campo à permanência e resistência camponesa pela via da educação

para se agregar a compreensão da influência da educação na afirmação do modo de vida camponês.

Assim, faz-se necessário analisar a totalidade que envolve as relações da vida camponesa, para que, posteriormente, se possa compreender, pelas particularidades, a real necessidade de busca do conhecimento pela educação, como estratégia de se preservar a identidade cotidiana do homem camponês, que por vezes é subjugada à lógica desenfreada do capital e das metamorfoses nos espaços e no trabalho, que pela perversidade do convencimento ideológico, flexibilizam e alteram seus modos próprios de vida.

Para Menezes Neto (2009), o debate que gira em torno da educação do campo é provido por interesses antagônicos entre as classes sociais. Esses interesses se materializam pelo agronegócio, de um lado, e pelo projeto camponês de Educação do Campo, do outro. Concepções de mundo antagônicas, vão, consequentemente, resultar em interesses políticospedagógicos distintos. A educação para o campo, sob a ótica do agronegócio, tem a intenção de configurar sujeitos que tenham funcionalidade à reprodução ampliada do capital, abarcando as ideologias impostas pelo sistema dominante, fazendo com que as desigualdades sociais sejam perpetuadas e se mantenha a sociedade dividida em classes. Contrapondo a este ponto de vista, a educação camponesa tem buscado a formação de indivíduos que não se fragmentem na sua totalidade e que tenham a oportunidade de compreender as relações humanas tanto na sua diversidade cultural quanto nas desigualdades sociais, econômicas e políticas, instauradas pelo capital.

Nessa perspectiva, Camacho (2012) coloca que se faz necessário reafirmar a essência do projeto de Educação do Campo no atual momento histórico, já que concepções distintas, como expressão de projetos distintos de sociedade, encontram-se em disputa. Assim reafirma a concepção de Educação do Campo umbilicada às práticas de luta dos movimentos sociais camponeses. A essência da Educação do Campo está atrelada à luta pela reforma agrária, contra o latifúndio, e pela superação das contradições da lógica do capital.

A conflitualidade inerente à lógica de reprodução do capitalismo no campo, que desemboca na disputa por territórios materiais e imateriais entre o agronegócio e os movimentos socioterritoriais camponeses, é um dos elementos centrais que fundamenta a produção de nossa análise teórica acerca do campo e da Educação do Campo. É esta contradição de classe que movimenta a história e resulta em uma produção do conhecimento científico a partir de diferentes perspectivas (CAMACHO, 2012, p.4-5). 
Entende-se, portanto, que o projeto de educação do campo está atrelado aos debates da questão agrária, onde as classes dominantes concebem, ideologicamente, a ideia do fim do campesinato para que possa instruir sujeitos funcionais a ótica de produção ampliada do capital. Em contraponto, a educação do campo visa a formação dos sujeitos camponeses, para que possam garantir as condições de reprodução do seu modo de vida. Discutindo a lógica capitalista de modernização do campo, pela via da difusão da tecnologia, e das relações de trabalho existentes, aponta-se a luta camponesa pela terra de trabalho e o desenvolvimento de um projeto educacional do campo como formas fundamentais de reprodução do campesinato e de exacerbação das contradições societais da produção de mercadorias, quiçá sua superação.

\section{5- Considerações finais}

A expansão das relações capitalistas no campo - via incrementos financeiros e tecnológicos - representada, nas últimas décadas pelo agronegócio se estabelece nas suas contradições. Primeiro porque se coloca como a forma única e fundamental sobre a qual toda a produção do campo deve adequar-se, sobrepondo-se ao conteúdo histórico que nos permite compreender outras formas de viver e produzir no campo que não aquelas eminentemente ditadas pela produção do capital. Segundo porque nega as próprias contradições desse modo de produção, que historicamente reproduz e se apropria das relações não capitalistas de produção como forma de garantia da renda da terra e do lucro.

No entendimento das contradições que se colocam no processo de reprodução do capital no campo ressalta-se que a difusão do agronegócio não se constitui na única forma das classes dominantes - proprietárias se reproduzirem no campo brasileiro. É necessário ainda criar as condições de se apropriar da efetiva produção camponesa - viabilizada nas pequenas e médias unidades de produção. Assim, o discurso da modernização e da difusão de tecnologias direcionadas para tais sujeitos se torna uma realidade, desde que a produção seja totalmente subsumida aos desígnios da produção de mercadorias.

Por outro lado, partindo-se da leitura da realidade vivenciada no campo brasileiro, não se pode aceitar que os camponeses apenas se submetem ao que o mercado define. Esses sujeitos também lutam pela permanência de sua terra de trabalho, se reproduzindo com relativa autonomia, ainda que parcialmente estabelecendo relações com o mercado. Estes também se colocam enquanto classe social, enfrentando os projetos do capital através de 

educação

ações que, efetivamente, defendem seu modo de vida, seus valores e formas de produzir no campo.

Portanto, conclui-se que o discurso da tecnologia no campo atende única e exclusivamente aos interesses dominantes e no geral, para as unidades de produção camponesa, representa formas de sujeição da renda e conversão do camponês em mera força de trabalho para o capital. Assim, é necessário ao campesinato lutar pela permanência de seu modo de vida e, mais que isso, de sua condição de classe social, construindo um projeto de sociedade, e para o campo brasileiro, onde os resultados da produção possam significar, efetivamente, melhorias para aqueles sujeitos que vivem do trabalho. Isso implica, diretamente, um enfrentamento ao capital, ao agronegócio e a agricultura familiar.

Nesse processo, a busca por uma educação efetivamente do campo se coloca como um projeto político de luta e resistência camponesa - contra o capital e sua forma mais recente de realização no campo - o agronegócio, contra tentativa de redução de seu modo de vida e seu poder político de classe ao conceito de agricultor familiar, mera força de trabalho para o capital e na construção de um projeto para o campo fundamentado nas necessidades dos sujeitos que nesse se reproduzem.

\section{Referências}

ABRAmOVAY, Ricardo. Paradigmas do Capitalismo Agrário em Questão. São Paulo: HUCITEC/ANPOCS/UNICAMP, 1992.

CAMACHO, Rodrigo Simão. A Educação do Campo no paradigma da Questão Agrária: o Projeto Camponês de Educação. In: XXI ENCONTRO NACIONAL DE GEOGRAFIA AGRÁRIA, 2012, Uberlândia. Anais... Uberlândia: UFU, 2012.

CARVAlHO, Horácio Martins de. O Campesinato no Século XXI. Possibilidades e Condicionantes do Desenvolvimento no Campo Brasileiro. São Paulo: Vozes, 2005.

CONCEIÇÃO, Alexandrina Luz. A Questão Camponesa: o signo sob o olhar dialético. 1991. Dissertação (Mestrado em Geografia) - Núcleo de Pós-Graduação em Geografia, São Cristovão, Sergipe, 1991.

FERNANDES, Bernardo Mançano. Agricultura Camponesa e/ou Agricultura Familiar. In: XIII Encontro Nacional de Geógrafos. Anais... AGB. João Pessoa/PB, 2002. (ISSN 01030883).

LAMARCHE, Hugues. (Coord.). L'agriculture familiale - 1: Une réalité polymorphe. Paris, L’Harmattan, 1994, 304p.

. L'agriculture familiale - 2: Du mythe à laréalité. Paris, L'Harmattan, 1994, 303p.

\begin{tabular}{l|l} 
Revista RBBA & Revista Binacional Brasil Argentina
\end{tabular} 
LUXEMBUrgo, Rosa. A Acumulação do Capital. Contribuição ao Estudo Econômico do Imperialismo. Apresentação de Paul Singer; traduções de Marijane Vieira Lisboa e Otto Erich Walter Maas. $2^{\mathrm{a}}$ ed. São Paulo: Nova Cultural, 1985. (Os Economistas).

MARQUES, Marta Inez Medeiros. O conceito de espaço rural em questão. In: Revista Terra Livre, São Paulo: AGB, ano 18, nº. 19, Jul-dez, 2002. p. 95-112.

Atualidade do conceito de camponês. In: XII Encontro Nacional de Geógrafos. Anais... João Pessoa/PB, 2002a.

MARTINS, José de Souza. Os Camponeses e a Política no Brasil. São Paulo: Vozes, 1981.

MENEZES NETO, Antônio Júlio de. Formação de professores para a Educação do campo: projetos sociais em disputa. In: ANTUNES-ROCHA, Maria Izabel; MARTINS, Aracy Alves (Orgs.). Educação do Campo: desafios para a formação de professores. Belo Horizonte: Autêntica Editora, 2009. p. 25-37. (Coleção Caminho da Educação do Campo, 1).

MENDRAS, Henri. Sociedades Camponesas. Rio de Janeiro: Zahar Editores, 1978.

OLIVEIRA, Ariovaldo Umbelino de. As Transformações Territoriais Recentes no Campo Brasileiro. Prova do Concurso para provimento de cargo de Professor Titular. FFLCH-USP, 03/03/1998.

A agricultura Camponesa no Brasil. $4^{\mathrm{a}}$ ed. - São Paulo: Contexto, 2001. 164p.

SANTOS, Jânio Roberto Diniz dos. Relações de Produção e Modificações Sócio-espaciais no Centro-Sul de Sergipe e Litoral Norte da Bahia a partir da Citricultura (1960-2003). Dissertação (Mestrado em Geografia). Programa de Pós-Graduação em Geografia. Universidade Federal da Bahia. Salvador, 2003.

SHANIN, Teodor. A definição de Camponês: Conceituações e Desconceituações. In: Cadernos Cebrap, São Paulo, 1980.

La Classe Incomoda. Madrid: Alianza Editorial, 1993.

Os desafios futuros para o campesinato. Conferência realizada durante o III Simpósio Internacional de Geografia Agrária, IV Simpósio Nacional de Geografia Agrária e Jornada Orlando Valverde - Campesinato em Movimento. Londrina, 14 de outubro de 2007.

SILVA, José Graziano da. A Nova dinâmica da Agricultura Brasileira. Campinas: Instituto de Economia, 1996.

SILVA, Lenyra Rique da. A natureza contraditória do espaço geográfico. São Paulo: Contexto, 2001.

SOUZA, Suzane Tosta. Da negação ao discurso "hegemônico" do capital à atualidade da luta de classes. Camponeses em luta pelo território no Sudoeste da Bahia. Tese (Doutorado em Geografia). Núcleo de Pós-Graduação em Geografia (NPGEO). Universidade Federal de Sergipe. São Cristóvão, 2008. 715p.

THOMPSON, E. P. Costumes em Comum. São Paulo: Companhia das Letras, 2002. 
Da expansão tecnológica do capital no campo à permanência e resistência camponesa pela via da educação

\section{Notas}

\footnotetext{
${ }^{\mathrm{i}}$ Com base nas reflexões apontadas por Edward P. Thompson, 2002.

ii Não se tem, nesse artigo, a pretensão de aprofundar o debate sobre a ideologia do desenvolvimento regional. Para maiores esclarecimentos sobre o assunto consultar: OLIVEIRA, Francisco. Elegia para uma religião. SUDENE, Nordeste, Planejamento e Conflitos de Classes. $3^{\mathrm{a}}$ Ed. Rio de Janeiro: Paz e Terra, 1981. 132p. _ C Crítica à Razão Dualista - o Ornitorrinco. São Paulo: Boitempo Editorial, 2003. MARANHÃO, Silvio (Org). A Questão Nordeste. Estudos sobre Formação Histórica, Desenvolvimento e Processos Políticos e Ideológicos. Rio de Janeiro: Paz e Terra, 1984. SOUZA, Suzane Tosta. As investidas do capital no campo brasileiro através das ideologias do "desenvolvimento" e da "modernização". Para Onde!? (UFRGS), v. 3, p. 1-17, 2009

iii Portal do Agronegócio. O que é?. Disponível em: http://www.portaldoagronegocio.com.br/pagina/o-que-e. Acessado em 25/04/2017.
}

\section{Sobre os autores}

\section{Suzane Tosta Souza}

Professora da Universidade Estadual do Sudoeste da Bahia, participa dos grupos de pesquisa: Grupo de Pesquisa Trabalho, Mobilidade e Relação Campo Cidade (UESB/CNPq); Grupo de Pesquisa Estado, Capital, Trabalho e as Políticas de Reordenamentos Territoriais (UFS/CNPq); Grupo de Pesquisa Ideologia e Lutas de Classe (GEILC/UESB/CNPq).

\section{Guilherme Matos de Oliveira}

Professor da Universidade Estadual do Sudoeste da Bahia, participa dos grupos de pesquisa: Grupo de Pesquisa Trabalho, Mobilidade e Relação Campo Cidade (UESB/CNPq) e Grupo de Pesquisa Estado, Capital, Trabalho e as Políticas de Reordenamentos Territoriais (UFS/CNPq).

Bolsista FAPESB/ Iniciação Científica

\section{Joelma Miranda Coutinho de Souza}

Mestranda - PPGEO/Universidade Estadual do Sudoeste da Bahia

Grupo de Pesquisa Trabalho, Mobilidade e Relação Campo Cidade (UESB/CNPq) e Grupo de Pesquisa Estado, Capital, Trabalho e as Políticas de Reordenamentos Territoriais (UFS/CNPq).

\section{Bolsista CAPES}

